$$
\text { CONF. } 970806--2
$$

\title{
Mechanical Properties of Aluminized CoCrAlY Coatings in Advanced Gas Turbine Blades
}

\author{
J. Kameda ${ }^{+}$, T. E. Bloomer ${ }^{+}$, Y. Sugita ${ }^{*}$ A. Ito ${ }^{*}$ and S. Sakurai ${ }^{*}$ \\ ${ }^{+}$Ames Laboratory and Center for Advanced Technology Development, Iowa State \\ University, Ames, IA 50011 \\ "Electric Power R \& D Center, Chubu Electric Power Co., Nagoya, 458, Japan \\ ${ }^{\#}$ Mechanical Engineering Research Laboratory, Hitachi Ltd., Hitachi, 317, Japan
}

\begin{abstract}
The microstructure/composition and mechanical properties $\left(22-950^{\circ} \mathrm{C}\right)$ in aluminized $\mathrm{CoCrAlY}$ coatings of advanced gas turbine blades have been examined using scanning Auger microprobe and a small punch (SP) testing method. Aluminized coatings were made of layered structure divided into four regimes; (I) $\mathrm{Al}$ enriched and $\mathrm{Cr}$ depleted region, (II) $\mathrm{Al}$ and $\mathrm{Cr}$ graded region, (III) fine grained microstructure with a mixture of $\mathrm{Al}$ and $\mathrm{Cr}$ enriched phases and (IV) $\mathrm{Ni} / \mathrm{Co}$ interdifusion zone adjacent to the interface. SP tests demonstrated strong dependence of the deformation and fracture behavior on the various coatings regimes. Coatings I and II showed higher microhardness and easier formation of brittle cracks in a wide temperature range, compared to coatings III and IV. The coating III had lower room temperature ductility and conversely higher elevated temperature ductility than the coating IV due to a precipitous ductility increase above $730{ }^{\circ} \mathrm{C}$. The integrity of aluminized coatings while in-service is discussed in light of the variation in the low cycle fatigue life as well as the ductility in the layered structure.
\end{abstract}

Key Words: aluminized coatings, layered structure, small
scanning Auger microprobe DISTRIBUTION OF THIS DOCUMENT IS UNLIMITEO, 


\section{DISCLAMMER}

Portions of this document may be illegible in electronic image products. Images are produced from the best available original document. 


\section{Introduction}

Aluminum packing treatments have been applied to improve the resistance of coatings to elevated temperature environmental attack in advanced gas turbine blades [1]. While the formation of aluminum rich phases near the coating surface would mitigate the oxidation, the mechanical properties of aluminized coatings are inevitably deteriorated while in-service due to the microstructural/chemical evolution. In-service mechanical degradation of blade coatings can not be evaluated using the standard mechanical testing method because gas turbine blades have a complex geometry and the coating degradation is localized in the near surface regime. However, recent studies [2-4] have shown that the application of a small punch (SP) testing method in conjunction with scanning Auger microprobe (SAM) analysis enable us to well characterize the mechanical degradation controlled by the evolution of microstructure/composition in blade coatings.

The objective of this study is to investigate the microstructure/composition and mechanical properties of aluminized CoCrAlY coatings over substrates made of directionally solidified nickel base superalloys in land-based gas turbine blades using the SAM analysis and SP method.

\section{Experimental Method}

The materials used in this study were gas turbine blades made of directionally solidified modified René 80 substrates and aluminized coatings $(58.2 \% \mathrm{Co}-29.7 \% \mathrm{Cr}-11.8 \% \mathrm{Al}-0.3 \% \mathrm{Y})$. The coating thickness varied in a range from 200-250 $\mu \mathrm{m}$ depending on the location of the blades.

Disk-shaped SP specimens (6 $\mathrm{mm} \phi$ and $0.5 \mathrm{~mm}$ thick) were machined from the near surface region of blades. SAM specimens ( $3 \mathrm{~mm}$ wide, $2 \mathrm{~mm}$ thick and $10 \mathrm{~mm}$ long) along the longitudinal direction of blades were also extracted. The coating was located on a side of the SP and SAM specimens. Several coated SP specimens were prepared in order that the 
specimen surface could be located in various coating regions indicated later. Substrate SP specimens were prepared by machining off the coating.

Longitudinal sections of the SAM specimens were sputter-cleaned ( $3 \mathrm{keV}$ ) in $\mathrm{Ar}$ gas atmosphere $\left(5 \times 10^{-6} \mathrm{~Pa}\right)$. The first derivative Auger peak height of various elements on the sputter-cleaned surfaces was measured using a cylindrical mirror analyzer (5 keV) of Physical Electronics Model 660. The concentration of elements was estimated from the measured Auger signal intensity and the relative sensitivity factor of elements [5].

Specially designed specimen holders consisting of lower and upper dies, and clamping screws were used for SP tests [6]. Coatings were deformed in tension using a puncher with a hemispherical tip with a diameter of $2.4 \mathrm{~mm}$. SP tests were carried out in air in a temperature range from $22-950^{\circ} \mathrm{C}$ using the cross head speeds of $8 \times 10^{-6} \mathrm{~m} / \mathrm{s}$ in a screw-driven Instron testing machine. The details of elevated temperature SP testing apparatus are indicated in Ref. [2]. The yield strength $\left(\sigma_{y}\right)$ and ductility $\left(\varepsilon_{f}\right)$ can be determined from the load vs. deflection curve of the SP tests, as indicated elsewhere [7-9].

\section{Results and Discussion}

Layered microstructure resulting from aluminizing treatments was divided into four regimes designated by I-IV depending on the microstructure (Fig. 1). The profiles of chemical compositions of the aluminized coating and substrate near the interface examined by SAM are shown in Fig. 2. Coating I observed near the coating surface had higher contents of $\mathrm{Al}$ and lower contents of $\mathrm{Cr}$ than the nominal concentration. The $\mathrm{Co}$ content did not differ from the bulk in the coating $\mathrm{I}$. Thus it is clear that $\mathrm{Cr}$ was replaced by $\mathrm{Al}$ during the aluminizing treatment. The coating I revealed grain coarsening to some extent [9]. Coating II had graded compositions of $\mathrm{Al}$ and $\mathrm{Cr}$ with a slight drop of the $\mathrm{Co}$ content as a result of the interdifusion of $\mathrm{Cr}$ and $\mathrm{Al}$. Coating regime $\mathrm{III}$ contained fine grained microstructure 
associated with a mixture of $\mathrm{Cr}$ and $\mathrm{Al}$ enriched phases [9]. Coating IV in the vicinity of the interface possessed a graded composition resulting from the interdiffusion of $\mathrm{Co}$ and $\mathrm{Ni}$ between the coating and substrate. Distinct evolution of layered microstructure/composition in the coatings as well as substrates adjacent to the interface was observed during thermal ageing [9].

The mechanical properties of the various coating regimes were studied using the SP testing method. The yield strength was estimated from the yield load observed in the flow curve $[7,9]$. The temperature dependence of $\sigma_{y}$, normalized by that in the substrate at RT, for the various coating regimes and substrate is shown in Fig. 3. In the substrate, the yield strength remained constant up to $800^{\circ} \mathrm{C}$ and then started to drop. In the $\mathrm{Al}$ enriched coatings $\mathrm{I}$ and $\mathrm{II}$, brittle cracks easily formed prior to the occurrence of plastic deformation. The fracture strength of the coatings I and II (indicated by asterisk marks) is plotted in Fig. 3. It also must be pointed out that the near surface $\mathrm{Al}$ enriched coatings had much higher microhardness compared with the other coating regimes [9]. Coated SP specimens (III and IV) indicated lower yield strength than substrate ones. The coating IV had higher yield strength than the regime III. The coatings III and IV showed hardening at $650-730{ }^{\circ} \mathrm{C}$ and $730-800{ }^{\circ} \mathrm{C}$, respectively. The yield strength of the coating IV and substrate converged with each other above $730^{\circ} \mathrm{C}$

The ductility for the coatings and substrate was defined at the crack initiation stage [79]. The variations of the ductility, normalized by that in the substrate at RT, for the blade to the testing temperature are illustrated in Fig. 4. The substrate had the highest RT ductility and a ductility trough at $800^{\circ} \mathrm{C}$. The Al enriched coatings I and II showed very low ductility in a wide testing temperature range although the coating II had an increase in the ductility at $950^{\circ} \mathrm{C}$. The coating IV containing Ni had a little higher RT ductility than the coating III with 
a mixture of $\mathrm{Al}$ and $\mathrm{Cr}$ enriched phases. However, the coating III had stronger temperature dependence of the ductility than the coating IV. Above $730{ }^{\circ} \mathrm{C}$, the coating III had a precipitous increase in the ductility. The ductility in the coating IV converged with that in the substrate above $800^{\circ} \mathrm{C}$. From Fig. 4 , it is evident that the substrate and coating IV containing $\mathrm{Ni}$ had better RT ductility than the other coating regimes without $\mathrm{Ni}$. Conversely, the $\mathrm{Ni}$ containing substrate and coating IV had lower ductility at elevated temperature, compared to the coating III. This observation is consistent with that reported by Strang and Lang [10].

The morphologies of coating cracking in SP specimens load-interrupted at RT and elevated temperatures can now be summarized [9]. Brittle cracks in the coatings I-III predominantly propagated along the radial direction at $\mathrm{RT}$ while crack branching occurred in a random direction in the coating IV. The density of cracks increased in order of the coatings I-IV. The substrate showed more discrete nucleation of cracks at dispersed precipitates. At elevated temperatures, the coating I revealed intergranular cracking and the coating II mainly fractured in a transgranular mode with a small mixture of intergranular cracking. High temperature cracking discontinuously occurred in the coatings III and IV.

It is apparent from the SP tests that brittle cracks readily formed in the near surface $\mathrm{Al}$ enriched coatings having good resistance to elevated temperature oxidizing attack. The engineering question is whether or not shallow cracks initiated near the surface would further extend into the regime III with higher ductility while in-service. The allowance of coating cracks is related to the stress component in gas turbine blades. The blade coatings of gas turbines are subject to larger thermal stresses produced by internal cooling than the stress applied by combustion gases. The tensile thermal stress is built up in the blade coatings in a certain temperature range during the start-up and shut-down transient operation of gas turbines whereas the compressive thermal stress is mainly operative during the normal 
operation [11]. However, the temperature distribution near rotating blades internally cooled has not yet been accurately evaluated [12]. Thus it is difficult to quantitatively estimate the maximum tensile stress and critical temperature range where the tensile thermal stress emerges in the coatings.

Combined cycle gas turbines in electric generating stations have been frequently operated under the transient condition. Thus the integrity of blade coatings is strongly controlled by the thermal fatigue behavior. The low cycle fatigue (LCF) behavior of the aluminized coatings at RT has been recently studied under constant displacement [9]. The LCF life in the coating I was found to be much lower, compared to that in the coating III as expected from the RT ductility result. In addition, the coating III had more brittle cracking features and weaker dependence of the LCF life on the strain amplitude than the CoNiCrAlY coatings despite similar RT ductility in both the coatings [3,9]. A further study on the LCF life of the coating III at elevated temperatures will be required to ensure the crack tolerance under the thermal fatigue condition. On the other hand, under the steady state operation the tensile thermal stress becomes minimal in the blade coatings. The environmental attack resistance would play a major role in the integrity of blade coatings. It has been shown [9] that surface cracks formed in the coating I during short time creep tests in air at $870{ }^{\circ} \mathrm{C}$ were more preferentially oxidized, compared to the coating surface, due to the strong interaction of oxygen with dislocations. Hence there is a need to clarify how the oxidation near the crack tip affects the elevated temperature fracture properties in the coating III.

Regardless of the uncertainty of the tensile thermal stress, the critical temperature and the oxidizing effect, it is most likely that cracks formed near the coating surface would not grow much into the coating III with high ductility at elevated temperatures. Moreover, the SP testing method in conjunction with the SAM analysis could be useful for optimizing 
coating constituents while compromising the oxidizing resistance and mechanical properties under monotonic and cyclic loading.

\section{Conclusions}

Small punch tests have clearly shown that the deformation and fracture behavior strongly varied depending on the graded microstructure/composition in aluminized coatings of advanced gas turbine blades. Coatings I ( $\mathrm{Al}$ enriched and $\mathrm{Cr}$ depleted region) an $\mathrm{II}$ ( $\mathrm{Al}$ and $\mathrm{Cr}$ graded region) with high microhardness showed easier formation of brittle cracks up to elevated temperatures than coatings III (fine grained region with $\mathrm{Al}$ or $\mathrm{Cr}$ enriched phases) and $\mathrm{IV}(\mathrm{Ni} / \mathrm{Co}$ interdifusion zone). The coating III had stronger temperature dependence of the ductility and better elevated temperature ductility, compared to the region IV. The effectiveness of aluminized coatings consisting of the layered structure is discussed in light of the environmental attack resistance and mechanical performance.

\section{Acknowledgments}

Ames Laboratory is operated for the US Department of Energy, Iowa State University under contract No. W-7405-ENG-82. The authors are grateful to A. H. Swanson and J. DeGabrialle at Ames Laboratory for assistance on the experimental work.

\section{References}

1. P. C. Patnaik, Advances in High Temperature Structural Materials and Protective Coatings, A. K. Koul, V. R. Parameswaran, J. P. Immarigeon and W. Wallace, eds., National Research Council of Canada, Ottawa, 1994, p. 169

2. Y. Sugita, M. Ito, S. Sakurai, N. Isobe, C. R. Gold, T. E. Bloomer and J. Kameda, Mater. Manuf. Proc., 10-5 (1996) 987.

3. Y. Sugita, M. Ito, S. Sakurai, C. R. Gold, T. E. Bloomer and J. Kameda, Materials Ageing and Component Life Extension, V. Bicego, A. Nitta and R. Viswanathan, eds., 
EMAS, West Midland, 1996, p. 307

4. J. Kameda, T. E. Bloomer, Y. Sugita, M. Ito and S. Sakurai, Mater. Sci. Eng., A, in press.

5. M. P. Seah, Practical Surface Analysis by Auger and X-Ray Photoelectron Spectroscopy, B. Briggs and M. P. Seah, eds., Willey, New York, NY, 1983, p. 181.

6. J. M. Baik, J. Kameda and O. Buck, Scripta Metall., 17 (1983) 1143.

7. X. Mao and H. Takahashi, J. Nucl. Mater., 150 (1987) 42.

8. J. Kameda and X. Mao, J. Mater. Sci., 27 (1992) 983.

9. J. Kameda and T. E. Bloomer, unpublished work, at Ames Laboratory and CATD, Iowa State University, 1996.

10. A. Strang and E. Lang, High Temperature Alloys for Gas Turbines, R. Brunetaud, D. Coutsouradis, T. B. Gibbons, Y. Lindblom, D. B. Meadowcroft and R. Stickler, eds., Reidal Publishing Co. London, 1982, p. 469.

11. L. H. Bernstein, et al., Thermomechanical Fatigue Behavior of Materials, H. Sehitoglu, ed., STP 1186, American Society for Testing Materials, Philadelphia, PA, 1993, p. 212.

12. N. S. Cheruvu, T. J. Carr, J. Dworak and J. Coyle, JOM, 48-5 (1996) 34.

\section{DISCLAIMER}

This report was prepared as an account of work sponsored by an agency of the United States Government. Neither the United States Government nor any agency thereof, nor any of their employees, makes any warranty, express or implied, or assumes any legal liability or responsibility for the accuracy, completeness, or usefulness of any information, apparatus, product, or process disclosed, or represents that its use would not infringe privately owned rights. Reference herein to any specific commercial product; process, or service by trade name, trademark, manufacturer, or otherwise does not necessarily constitute or imply its endorsement, recommendation, or favoring by the United States Government or any agency thereof. The views and opinions of authors expressed herein do not necessarily state or reflect those of the United States Government or any agency thereof. 


\section{Figure Captions}

Figure 1. Micrograph indicating layered structure of aluminized coating divided into four coating regimes (I-IV).

Figure 2. Profiles of composition of alloying elements in aluminized coatings and near interface substrate

Figure 3. Temperature dependence of yield strength $\left(\sigma_{y}\right)$ in coatings III and IV and substrate. An asterisk mark indicates the fracture strength for coatings I and II. The yield and fracture strength are normalized by $\sigma_{\mathrm{y}}$ in substrate at RT.

Figure 4. Temperature dependence of ductility $\left(\varepsilon_{f}\right)$ in coatings I- IV and substrate. The ductility is normalized by that in substrate at RT. 

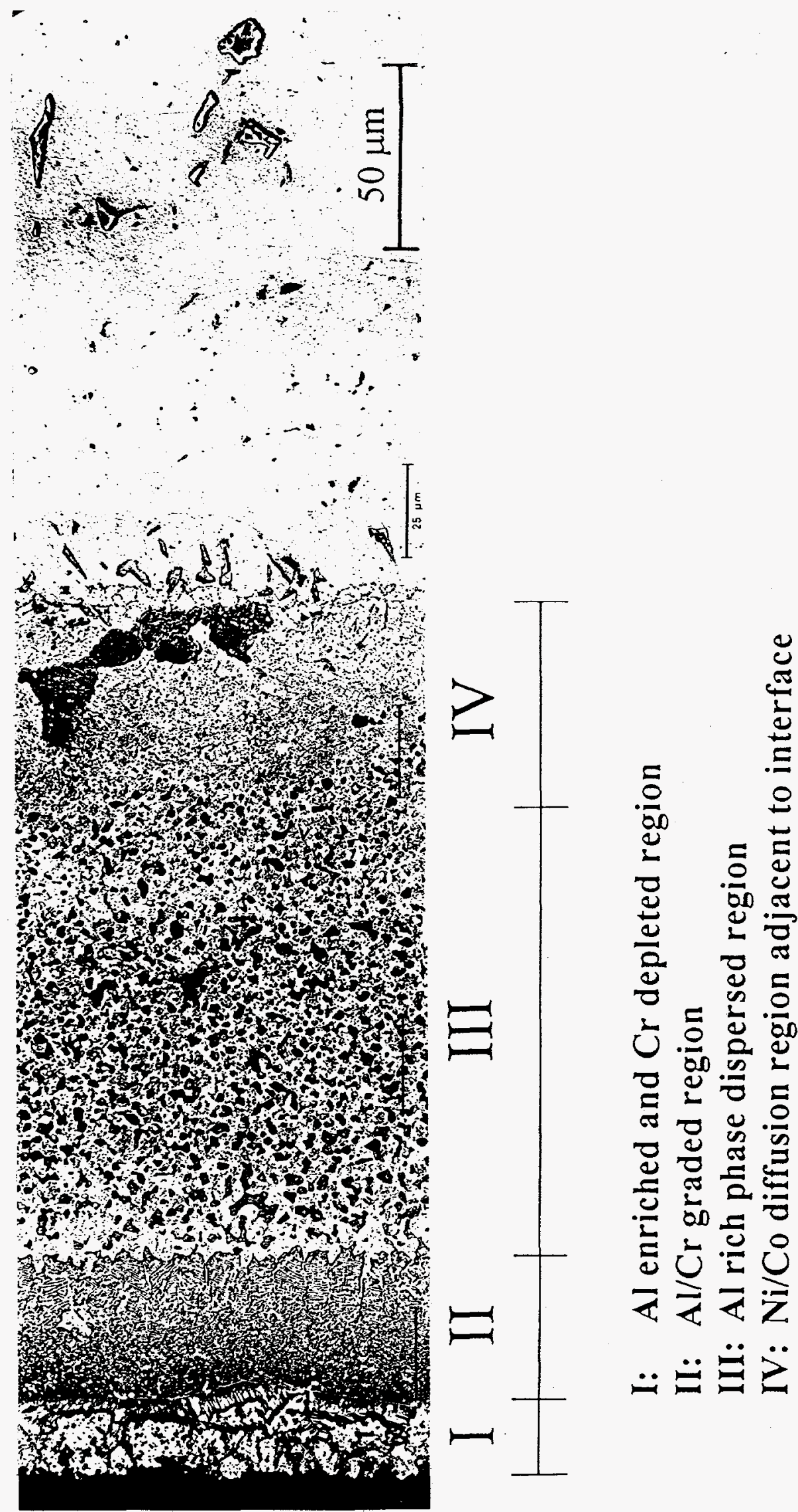
必

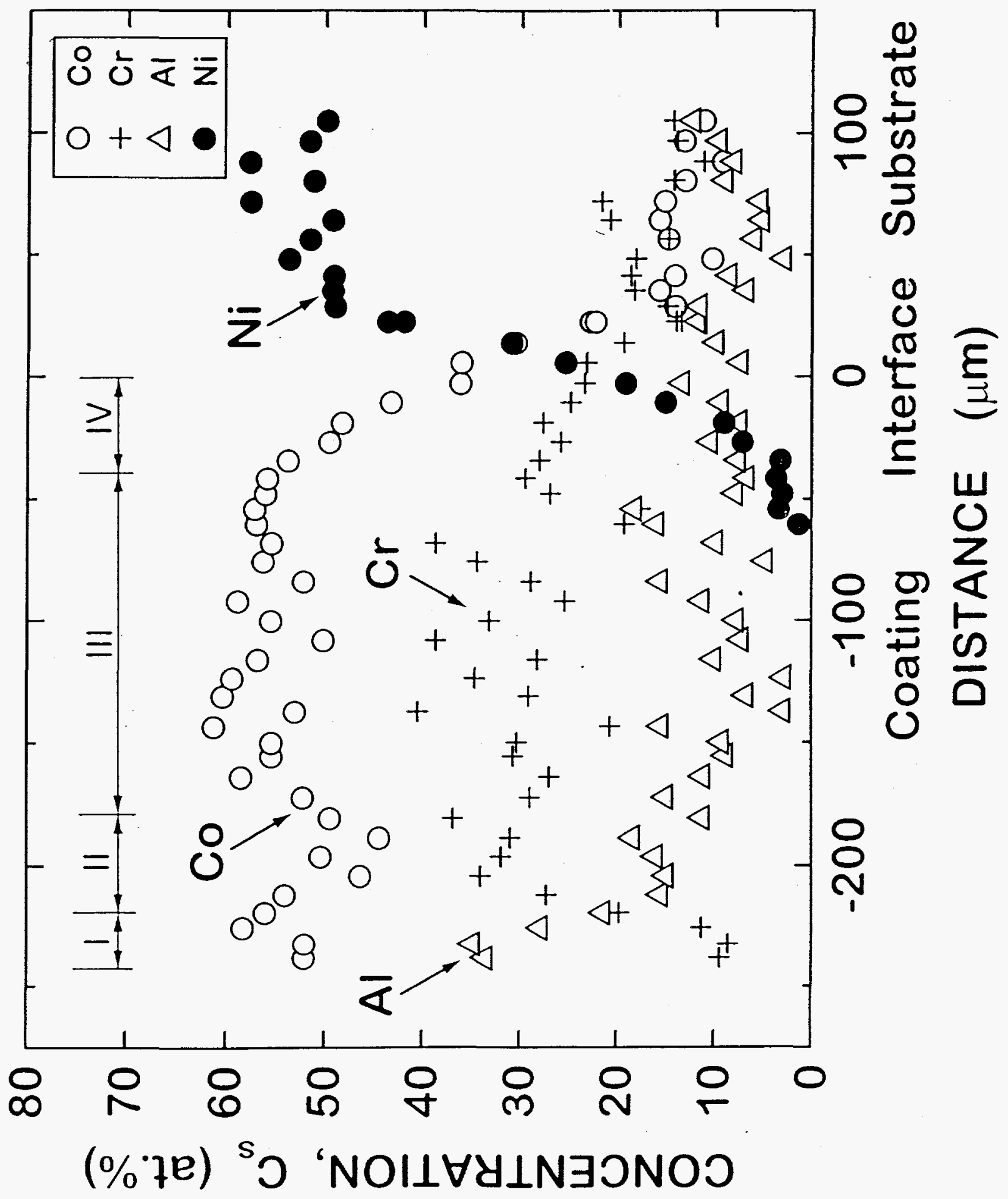




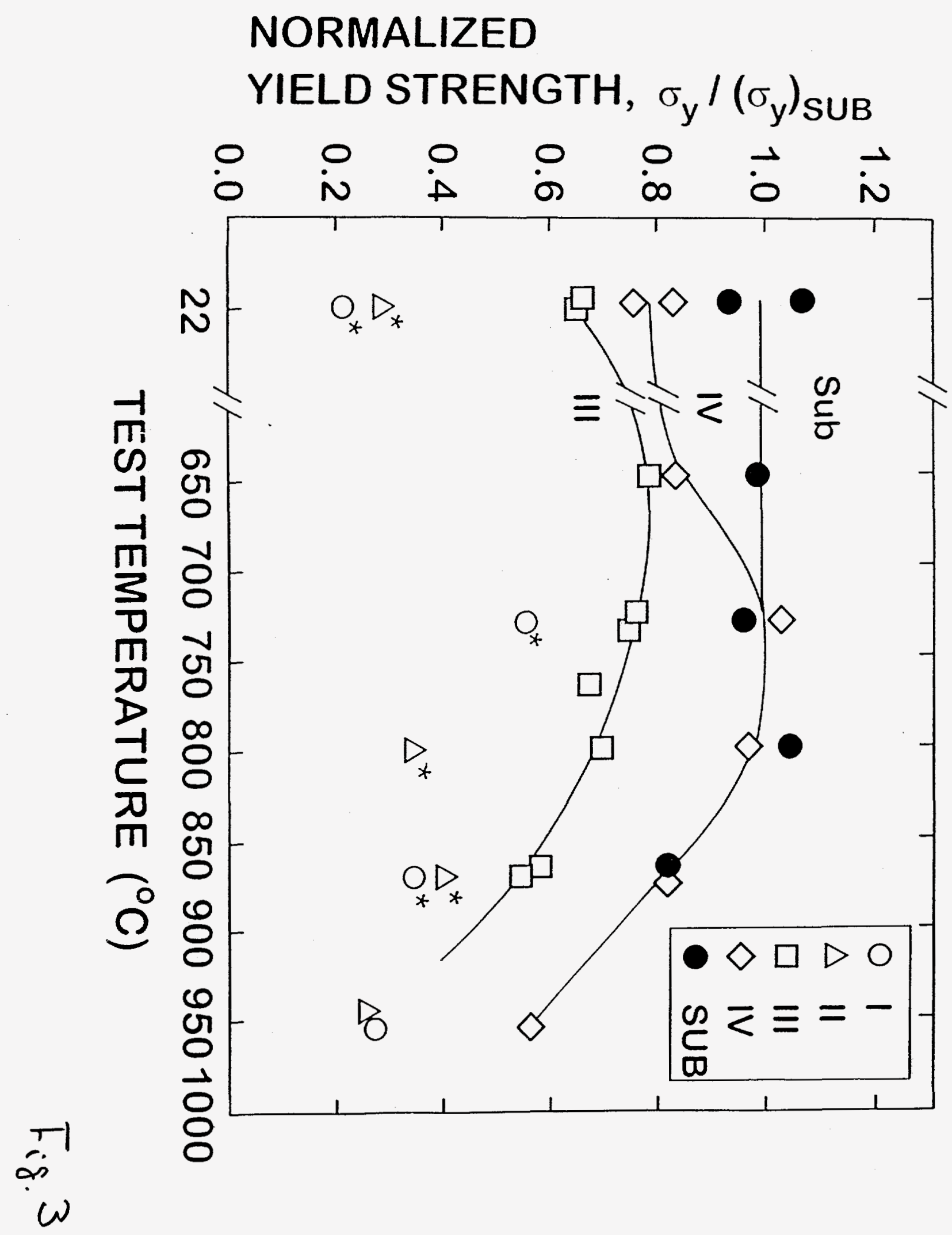




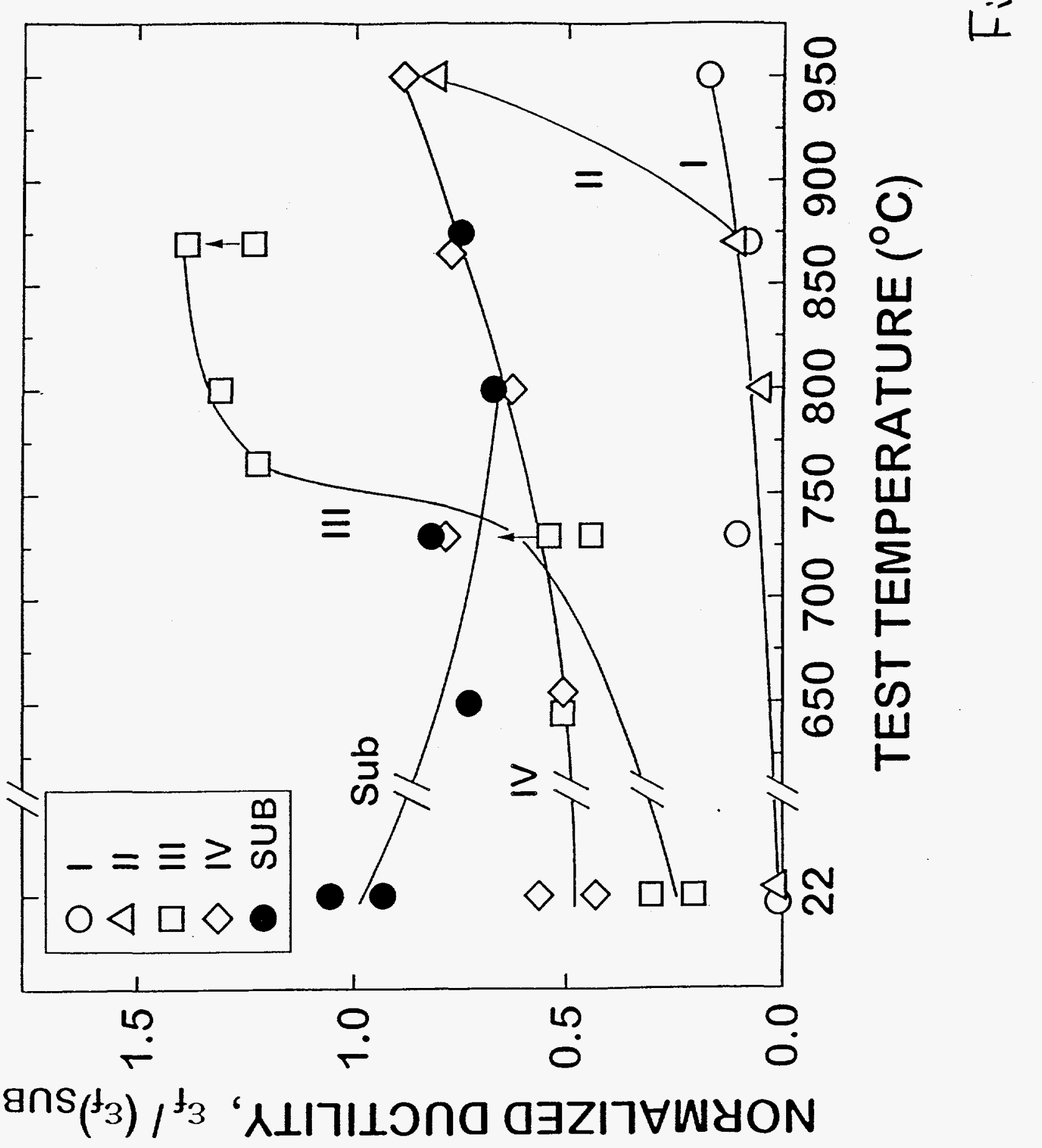

